\title{
Photochemical generation of manganese(IV)-oxo porphyrins by visible light photolysis of dimanganese(III) $\mu$-oxo bis-porphyrins
}

\author{
Ka Wai Kwong, Charles M. Winchester and Rui Zhang* \\ Department of Chemistry, Western Kentucky University, Bowling Green, KY 42101-1079, USA
}

* Corresponding author: Rui Zhang, Department of Chemistry, Western Kentucky University, 1906 College Heights Blvd \#11079, Bowling Green, KY 42101-1079, Phone: 270-745-3803, Fax: 270-745-55361, e-mail: rui.zhang@wku.edu 


\begin{abstract}
Visible light photolysis of dimanganese(III) $\mu$-oxo bis-porphyrins, $\left[\mathrm{Mn}^{\mathrm{III}}(\mathrm{Por})\right]_{2} \mathrm{O}$, was studied in three porphyrin systems with different electronic structures. Direct conversion of manganese (III) $\mu$-oxo dimers to manganese(IV)-oxo porphyrins plus manganese(III) products has been observed in benzene solution upon light irradiation. The spectral signature of $\mathrm{Mn}^{\mathrm{IV}}$ (Por)(O) was further confirmed by production of the same species in the known experiment of the $\mathrm{Mn}^{\mathrm{III}}(\mathrm{Por}) \mathrm{Cl}$ with $\mathrm{PhI}(\mathrm{OAc})_{2}$. Continuous irradiation of dimanganese(III) $\mu$-oxo bisporphyrins in the presence of pyridine or triphenylphosphine gave rise to the formation of $\mathrm{Mn}^{\mathrm{II}}$ (Por)(Py) or $\mathrm{Mn}^{\mathrm{II}}(\mathrm{Por})\left(\mathrm{PPh}_{3}\right)$ which were stable to be detected. A photo-disproportionation mechanism similar to that for diiron(III) $\mu$-oxo bis-porphyrins was proposed to explain above photochemical behaviors of the three dimanganese(III) $\mu$-oxo bis-porphyrins.
\end{abstract}

\title{
Key Words
}

Dimanganese(III) $\mu$-oxo bis-porphyrins; manganese(IV)-oxo porphyrin; disproportionation; visible light 


\section{Introduction}

Catalytic oxidation is a pivotal transformation for chemical synthesis in organic laboratories and petrochemical industries.[1, 2] In Nature, the ubiquitous cytochrome P450 enzymes (P450s) can catalyze a wide variety of oxidation reactions with exceptionally high reactivity and selectivity.[3, 4] In the past decades, many transition metal catalysts bearing a core structure resembling the iron porphyrin core of P450s, have been synthesized as models to probe the sophisticated mechanism of molecular oxygen activation as well as to invent enzyme-like oxidation catalysts.[5-8] In general, high-valent transition metal-oxo species have been implicated as the active oxidizing species. $[9,10]$ In particular, manganese-oxo intermediates are among the more reactive oxidizing transition metal derivatives. A variety of these species are employed catalytically in applied syntheses, [5, 6] and Nature uses Mn-oxo species in the production of oxygen in photosynthesis II.[11] Highly reactive porphyrin-manganese(V)-oxo derivatives $[12,13]$ are proposed intermediates in catalytic processes that have been known for decades.[14, 15] In contrast, the well-characterized manganese(IV)-oxo derivatives are less reactive than manganese(V)-oxo species in manganese porphyrin-catalyzed oxidations.[16-18]

Photochemistry is particularly intriguing to explore the metal-oxo chemistry.[19, 20] With photochemical production of reactive metal-oxo transients, one has access to time scales that are much shorter than the fastest mixing experiments. Furthermore, kinetics of oxidation reactions of transients of interest are not convoluted with the kinetics of reactions that form the transients. In this regard, laser flash photolysis (LFP) techniques have been successfully developed for generation and direct kinetic studies of a variety of high-valent transition metaloxo species supported by porphyrin and corrole ligands.[21-26] In so-called photo-induced ligand cleavage reactions, both porphyrin-manganese(IV)-oxo species and porphyrinmanganese(V)-oxo species can be produced as a function of the identity of the axial ligands. For examples, irradiation of porphyrin-manganese(III) nitrates and chlorates resulted in homolytic cleavage of the $\mathrm{O}-\mathrm{X}$ bonds in the ligands to afford porphyrin-manganese(IV)-oxo species, whereas irradiation of porphyrin-manganese(III) perchlorates resulted in heterolytic cleavage of O-Cl bonds to give porphyrin-manganese(V)-oxo cations.[27]

Notably, the chemistry of cofacial metal-bis-porphyrins has drawn increased attention owing to the ability of these systems to utilize molecular oxygen and visible light (sunlight) for organic oxidations.[28, 29] One example is the catalytic aerobic oxidation by high-valent 
iron(IV)-oxo species in a process that involves photo-disproportionation of a diiron(III)- $\mu$-oxo bis-porphyrin complex.[30, 31] The catalytic efficiency of diiron(III)- $\mu$-oxo systems was improved by employing "Pacman" ligand designs with organic spacer-hinges, which can preorganize two iron centers in a favorable co-facial arrangement.[32-35] In a similar fashion, we discovered that photolysis of a bis-corrole-iron(IV) $\mu$-oxo dimer apparently proceeded by the same type of photo-disproportionation mechanism to give corrole-iron(V)-oxo transient.[36, 37] In addition, we reported a putative porphyrin-ruthenium(V)-oxo species generated in a similar photo-disproportionation process that has shown great potential for aerobic photocatalytic oxidations.[38, 39] Herein, we report direct spectroscopic observation of photochemical generation of porphyrin-manganese(IV)-oxo complexes by visible light irradiation of bisporphyrin-manganese(III) $\mu$-oxo dimers. The results in the current study support the conclusion that bis-porphyrin-manganese(III) $\mu$-oxo dimers undergo photo-disproportionation reaction upon light irradiation to generate a germinal porphyrin-manganese(II)/manganese(IV)-oxo pair that can be detected and studied in real time (Scheme 1).
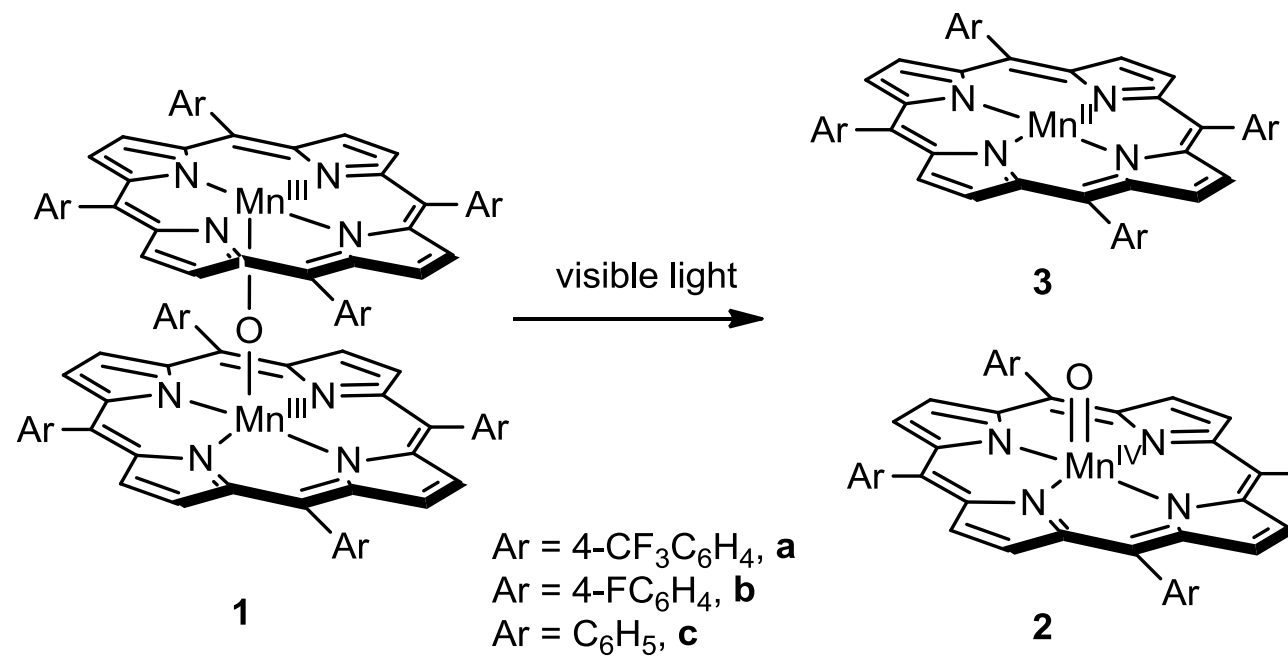

3

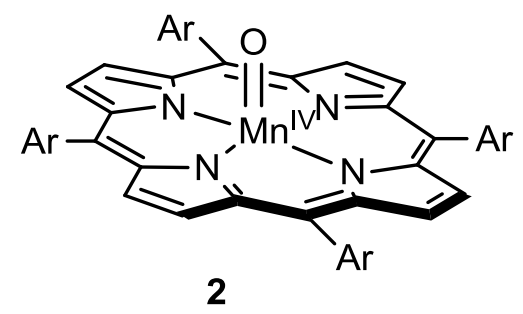

Scheme 1. Visible light photolysis of bis-porphyrin-manganese(III) $\mu$-oxo dimers to produce a germinal porphyrin-manganese(II)/manganese(IV)-oxo pair in three porphyrin systems 


\section{$2 \quad$ Results and discussions}

\subsection{Synthesis and spectral studies of bis-porphyrin-dimanganese(III) $\mu$-oxo complexes (1)}

As shown in Scheme 1, three porphyrin systems, 5,10,15,20-tetrakis(4-trifluoro methylphenyl)porphyrin (4-CF 3 TPP, a), 5,10,15,20-tetrakis(4-fluorophenyl)porphyrin (4-FTPP, b) and 5,10,15,20-tetraphenylporphyrin (TPP, c), were studied in this work. Abbreviations used here follow those conventionally established. All ligands a-c are generally considered as a sterically non-encumbered porphyrin due to the absence of substituents on the ortho positions of the meso-phenyl groups. The different aromatic groups on the porphyrins also result in varying electron demands with the trifluoromethylphenyl system being the most electron withdrawing.

Following a known procedure,[40] three bis-porphyrin-dimanganese(III) $\mu$-oxo complexes (1) were synthesized by reacting a corresponding $\mathrm{Mn}^{\mathrm{III}}$ (Por)Cl with $\mathrm{NaOH}$ in benzene solutions. The formed products in three porphyrin systems are characterized by UV-visible and ${ }^{1} \mathrm{H}-\mathrm{NMR}$ spectra. The representative spectra of $\mathbf{1 a}$ are shown Fig. 1 and other spectra for $\mathbf{1 b}$ and 1c are shown in Fig S1 and S2 in the Supplementary Information. All bis-porphyrindimanganese(III) $\mu$-oxo complexes show distinct UV-vis absorption characterized by split Soret bands at approximate $425 \mathrm{~nm}$ and $474 \mathrm{~nm}$, respectively, consistent with reported values in the literature.[40] Interestingly, the non-oxidative transformation of manganese(III) monomer to its $\mu$-oxo dimer 1 was also identified by featuring paramagnetically shifted pyrrolic protons, which was slightly more downfield than that of manganese(III) monomer of $\mathrm{Mn}^{\mathrm{III}}$ (Por)Cl (Fig. 1B). Attempts to prepare some sterically hindered porphyrin $\mu$-oxo dimers which contain relatively large electron-donating substituents (including methyl and methoxy) at ortho position of the meso-phenyl rings were not successful, apparently due to the steric hindrance. As noticed in earlier reports, $[37,41]$ it was found that electron-withdrawing substituents such as $\mathrm{CF}_{3}$ and $\mathrm{F}$ on porphyrin ligand favor $\mu$-oxo dimer formation. Presumably, the electron-withdrawing groups could stabilize the metal complexes in a dimer form by reducing the electron density of metal atoms. It is noteworthy that compound $\mathbf{1}$ is significantly stable in non-polar solvents such as benzene or cyclohexane; however, in $\mathrm{CH}_{2} \mathrm{Cl}_{2}$ or acetonitrile solution, complex $\mathbf{1}$ is not stable and gradually returns to the monomeric $\mathrm{Mn}^{\mathrm{III}}$ complex (Fig S3 in the Supplementary Information). Apparently, the relatively weak Mn-O-Mn bond in dimeric complexes can be readily dissociated by these polar solvents. 

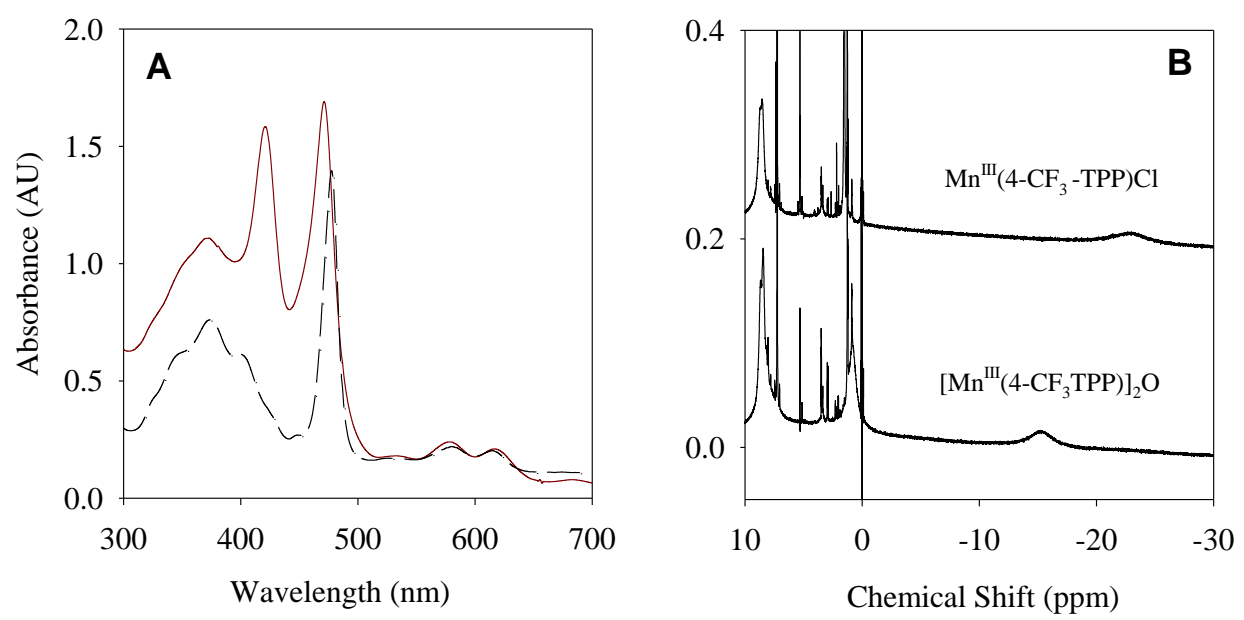

Fig. 1. (A) UV-vis spectra of manganese(III) chloro precursor $\mathrm{Mn}^{\mathrm{III}}\left(4-\mathrm{CF}_{3} \mathrm{TPP}\right) \mathrm{Cl}$ (dashed line) and bis-porphyrins dimanganese(III) $\mu$-oxo complex $\left[\mathrm{Mn}^{\mathrm{III}}\left(4-\mathrm{CF}_{3} \mathrm{TPP}\right)\right]_{2} \mathrm{O}$ (1a) (solid line) in benzene (B) ${ }^{1} \mathrm{H}-\mathrm{NMR}$ spectrum of $\mathrm{Mn}^{\mathrm{III}}\left(4-\mathrm{CF}_{3} \mathrm{TPP}\right) \mathrm{Cl}$ (top) and $\left[\mathrm{Mn}^{\mathrm{III}}\left(4-\mathrm{CF}_{3} \mathrm{TPP}\right)\right]_{2} \mathrm{O}$ (1a, bottom) in $\mathrm{CDCl}_{3}$.

\subsection{Visible light photolysis of bis-porphyrin-dimanganese(III) $\mu$-oxo dimers}

Visible light irradiation of $\mu$-oxo complex 1a in anaerobic benzene from a SOLA engine $(120 \mathrm{~W})$ gave rise to the formation of a transient species $\mathbf{2 a}$ with a slightly blue-shifted Soret band at $420 \mathrm{~nm}$. The absorption spectral changes shows that the twin peaks of 1 a located at 425 and $472 \mathrm{~nm}$ gradually decreased and a new peak at $420 \mathrm{~nm}$ appeared during the course of irradiation up to $3.5 \mathrm{~min}$ (Fig. 2A). Judging from the spectral changes and kinetic behavior, the transient species that formed at $420 \mathrm{~nm}$ could be ascribed to the manganese(IV)-oxo porphyrin, i.e. $\mathrm{Mn}^{\mathrm{IV}}\left(4-\mathrm{CF}_{3} \mathrm{TPP}\right)(\mathrm{O})$. Note that the absorption spectra of $\mathbf{2 a}$ overlap with that of another $\mathrm{Mn}^{\mathrm{III}}$ porphyrin which apparently gave a Soret band at $472 \mathrm{~nm}$ and partial absorption in the range of 370 to $415 \mathrm{~nm}$. The spectra signature of the photo-generated $\mathbf{2} \mathbf{a}$ as $\mathrm{Mn}^{\mathrm{IV}}\left(4-\mathrm{CF}_{3} \mathrm{TPP}\right)(\mathrm{O})$ was further confirmed by production of the same species from chemical oxidation of manganese(III) with $\mathrm{PhI}(\mathrm{OAc})_{2}$ as a mild oxidant (Fig. 2B).[42] When excess amounts of organic reductants such as cyclohexene or styrene were added to above solutions of $\mathbf{2 a}$, the UV-visible spectrum of 2a returned to that of manganese(III) porphyrin, which was recovered in > 90\% yield (Fig. 3). The overall reaction sequence is consistent for the behavior expected for porphyrin- 
manganese(IV)-oxo species.[42] In a similar fashion, irradiation of $\mathbf{1 b}$ with visible light also produced $\mathbf{2 b}$ in another porphyrin system (Fig. S4 in Supplementary Information). Although the complex 1c showed relatively low solubility in benzene solution, visible light irradiation of 1c gave similar results (data not shown) as compared to that of $\mathbf{1 a}$ and $\mathbf{1 b .}$
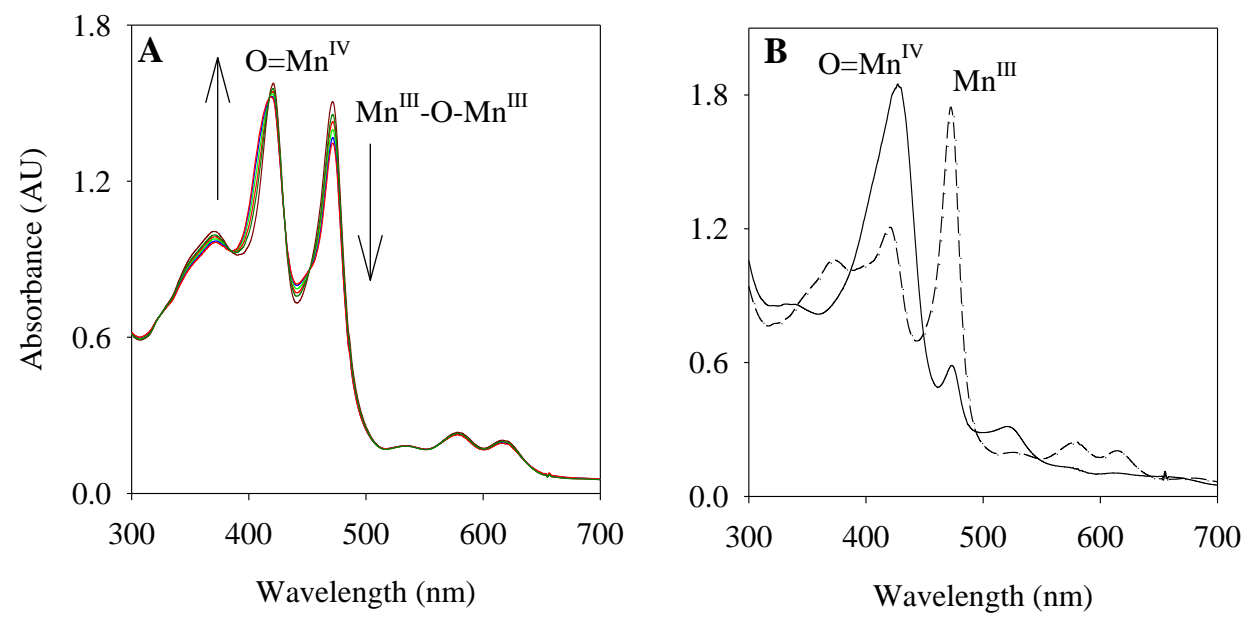

Fig. 2. (A) Time-resolved spectrum of $\mathbf{2 a}$ upon irradiation of 1a with a 120-W visible lamp in anaerobic benzene over $3.5 \mathrm{~min}$. at $23 \pm 2{ }^{\circ} \mathrm{C}$; (B) UV-visible spectrum of $2 \mathbf{a}$ (solid line) generated by reacting $\mathrm{Mn}^{\mathrm{III}}\left(4-\mathrm{CF}_{3} \mathrm{TPP}\right) \mathrm{Cl}$ (dash line) with $\mathrm{PhI}(\mathrm{OAc})_{2}$ (25 equiv.) in benzene at ambient temperature. 


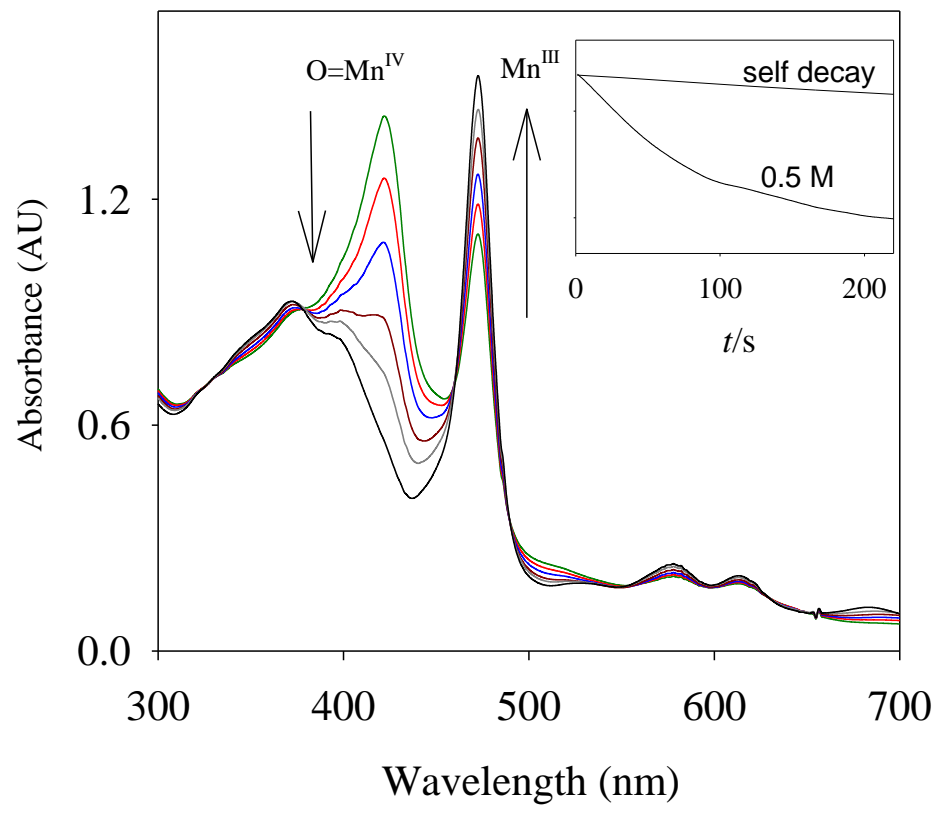

Fig. 3. Time-resolved spectra over $220 \mathrm{~s}$ for reaction of photo-generated $2 \mathbf{a}$ with $0.5 \mathrm{M}$ cyclohexene in benzene at $23 \pm 2{ }^{\circ} \mathrm{C}$; the inset shows the kinetic trace at $420 \mathrm{~nm}$ in the absence (self-decay) and presence of cyclohexene (0.5 M).

\subsection{Proposed mechanism}

Visible light photolysis of dimer 1 to produce manganese(IV)-oxo porphyrin $\mathbf{2}$ can be explained by a photo-disproportionation mechanism similar to that previously established for the photolysis of bis-porphyrin-diiron(III) $\mu$-oxo complexes.[30] As outlined in Scheme 2, photodisproportionation of dimer $\mathbf{1}$ gives the reactive manganese(IV)-oxo transient $\mathbf{2}$ in addition to one molecule of a porphyrin-manganese(II) species $\mathbf{3}$ and oxidation of an organic reductant by $\mathbf{2}$ gives a second molecule of $\mathbf{3}$. Species $\mathbf{3}$ was known to be unstable in aerobic media and tends to be rapidly oxidized to the manganese(III) complex (4).[20] Clearly, photolyses of dimanganese(III) $\mu$-oxo bis-porphyrins $\mathbf{1}$ appear to present a reaction manifold similar to that of diiron(III) $\mu$-oxo bis-porphyrins,[30] diruthenium(IV)- $\mu$-oxo bis-porphyrins[38] and diiron(IV)$\mu$-oxo bis-corroles.[37] In light of the current interest in photo-disproportionation reaction, the effects of electronic structure on the photolysis of manganese (III) $\mu$-oxo bisporphyrins and insights into the detailed intramolecular electron transfer process involved deserves further study 
including the theoretic support from computational calculations. These studies are expected to further our understanding of photo-disproportionation reactions in different systems.

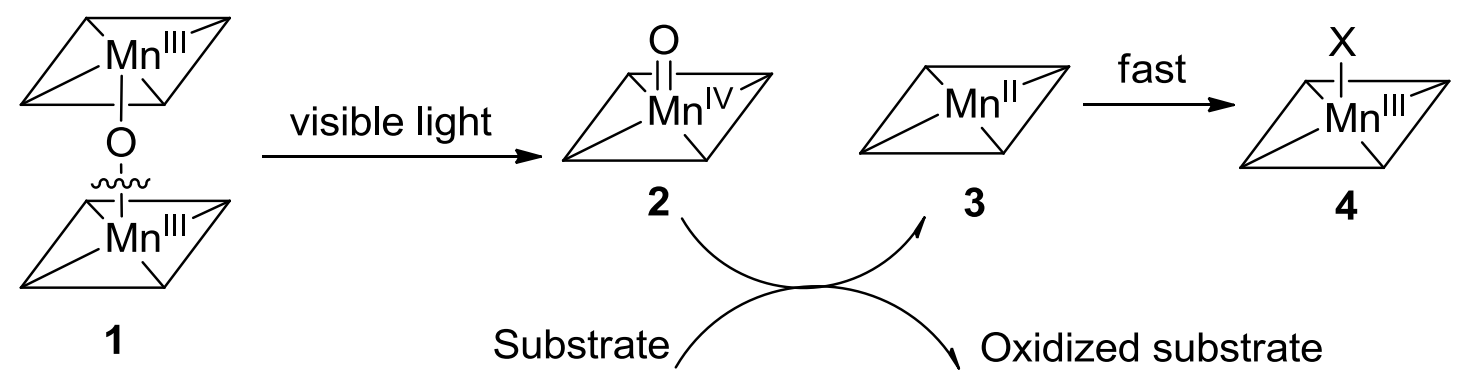

Scheme 2. A proposed photo-disproportionation mechanism (square represents the porphyrin ring)

2.4 Photolysis of bis-porphyrin-dimanganese(III) $\mu$-oxo dimers in the presence of pyridine and triphenylphosphine

To accentuate the proposed photo-disproportionation mechanism, irradiation of the thermally stable complex $\mathbf{1 a}$ in the presence of excess pyridine was conducted. Similar to the well-known photo-disproportionation of diiron(III)- $\mu$-oxo bis-porphyrin complexes,[30] the $\mu$ oxo precursor 1a gradually converted to a stable product 5a with well-anchored isosbestic points (Figure 4A). According to previous studies by Hoshino and coworkers, [43] the product 5a formed with $\lambda_{\max }$ at $440 \mathrm{~nm}$ was assigned as $\mathrm{Mn}^{\mathrm{II}}\left(4-\mathrm{CF}_{3} \mathrm{TPP}\right)(\mathrm{Py})$, which was further confirmed by production of the same species in the known experiment of the $\mathrm{Mn}^{\mathrm{III}}\left(4-\mathrm{CF}_{3} \mathrm{TPP}\right)\left(\mathrm{NO}_{2}\right)$ with excess pyridine.[43] The reactants and products of the overall photoreaction are matched to their respective absorption profiles. This photochemical observation of a clean reduction of $\left[\mathrm{Mn}^{\mathrm{III}} \text { (Por) }\right]_{2} \mathrm{O}$ to $\mathrm{Mn}^{\mathrm{II}}$ (Por)(Py) further supports a photo-disproportionation pathway that allows for the generation of the manganese(IV)-oxo porphyrin. Of note, similar spectral changes were also observed upon the photo-disproportionation of dimanganese(III)- $\mu$-oxo bis-porphyrin (1a) in the presence of excess $\mathrm{Ph}_{3} \mathrm{P}$ that gave another stable $\mathrm{Mn}{ }^{\mathrm{II}}\left(4-\mathrm{CF}_{3} \mathrm{TPP}\right)\left(\mathrm{PPh}_{3}\right)(\mathrm{Fig} 4 \mathrm{~B})$. 

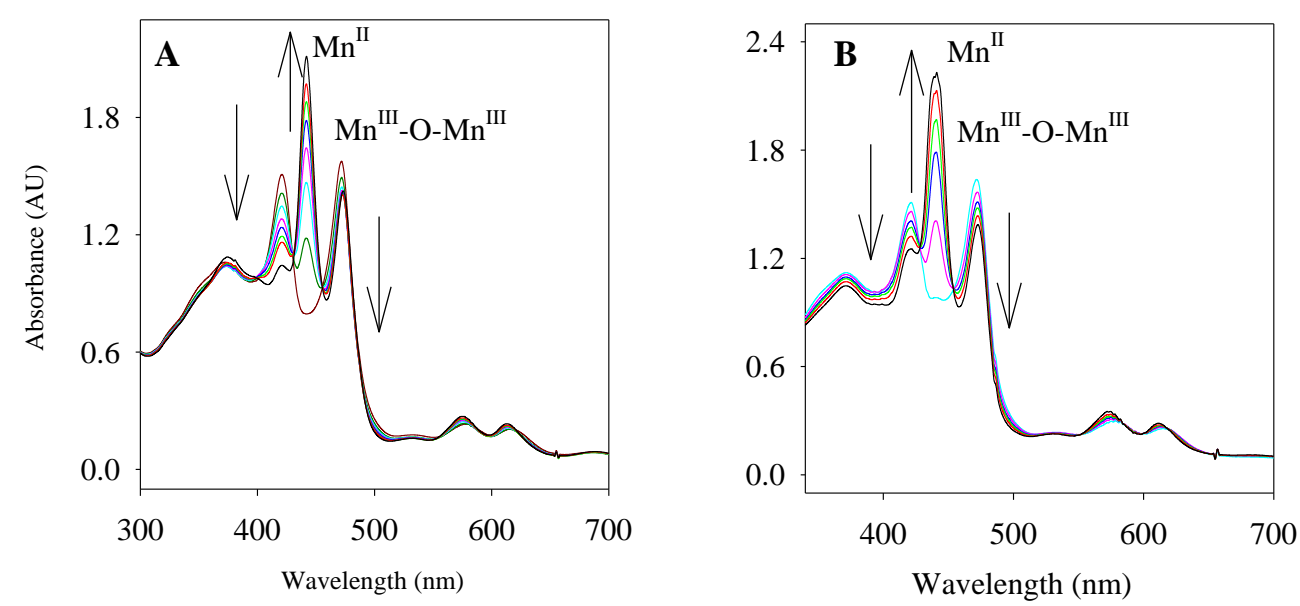

Fig. 4 (A) Time-resolved spectra of $\mathrm{Mn}^{\mathrm{II}}\left(4-\mathrm{CF}_{3} \mathrm{TPP}\right)(\mathrm{Py})$ generated by visible light irradiation of $\mathbf{1 a}$ in the presence of excess amount of pyridine $(3 \mathrm{mM})$ over $50 \mathrm{~min}$ in benzene; (B) Timeresolved spectra of $\mathrm{Mn}^{\mathrm{II}}\left(4-\mathrm{CF}_{3} \mathrm{TPP}\right)\left(\mathrm{PPh}_{3}\right)$ generated by irradiation of $\mathbf{1 a}$ in the presence of excess amount of triphenylphosphine $(3 \mathrm{mM})$ over $8 \mathrm{~min}$ in benzene. Visible light was produced from a $120-\mathrm{W}$ solar lamp.

\section{Conclusions}

In conclusion, photo-cleavage of bis-porphyrin-manganese(III) $\mu$-oxo dimers using visible light proceeds by homolysis of an $\mathrm{Mn}-\mathrm{O}$ bond to give manganese(IV)-oxo porphyrins that are spectroscopically indistinguishable from the species formed by chemical oxidation of the corresponding porphyrin-manganese(III) chlorides. In addition, continuous irradiation of dimanganese(III) $\mu$-oxo bis-porphyrins in the presence of pyridine or triphenylphosphine gave rise to the formation of $\mathrm{Mn}^{\mathrm{II}}(\mathrm{Por})(\mathrm{Py})$ or $\mathrm{Mn}{ }^{\mathrm{II}}(\mathrm{Por})\left(\mathrm{PPh}_{3}\right)$ that was also directly observed. The photochemical behavior of dimanganese(III) $\mu$-oxo bis-porphyrins upon irradiation is ascribed to a photo-disproportionation mechanism similar to that for diiron(III) $\mu$-oxo bis-porphyrins. Further studies to characterize the observed transients spectroscopically more fully are ongoing in our laboratory.

\section{$4 \quad$ Experimental}

\subsection{General considerations}


All commercial reagents were of the best available purity and were used as supplied unless otherwise specified. HPLC grade benzene (> 99.9\%) was purified by passing through a dry $\mathrm{Al}_{2} \mathrm{O}_{3}$ (Grade I neutral) column prior to use. Free porphyrin ligand including $\mathrm{H}_{2}\left(4-\mathrm{CF}_{3} \mathrm{TPP}\right.$ ) (a), $\mathrm{H}_{2}$ (4-FTPP)(b) and $\mathrm{H}_{2} \mathrm{TPP}(\mathbf{c})$ were prepared according to the known methods. [44] The corresponding manganese(III) chloride complexes $\mathrm{Mn}^{\mathrm{III}}$ (Por) $\mathrm{Cl}$ (Por $=\mathbf{a}-\mathbf{c}$ ) used for generation of $\left[\mathrm{Mn}^{\mathrm{III}}(\text { Por })\right]_{2} \mathrm{O}(\mathbf{1})$ were prepared by literature methods and characterized fully, matching those reported.[45] UV-vis spectra were recorded on an Agilent 8453 diode array spectrophotometer. ${ }^{1} \mathrm{H}-\mathrm{NMR}$ was performed on a JEOL ECA-500 MHz spectrometer at $298 \mathrm{~K}$ with tetramethylsilane (TMS) as internal standard. Chemical shifts (ppm) are reported relative to TMS. Visible light was produced from a SOLA SE II light engine (Lumencor) configured with a liquid light guide. The output power is $120 \mathrm{~W}$.

\subsection{Preparation of dimanganese(III) bis-porphyrins $\left[\mathrm{Mn}^{I I I}(\mathrm{Por})\right]_{2} \mathrm{O}$.}

In a typical run, $\left[\mathrm{Mn}^{\mathrm{III}}(\text { Por })\right]_{2} \mathrm{O}(\mathbf{1})$ was prepared by vigorously stirring $\mathrm{Mn}^{\mathrm{III}}$ (Por)Cl complex $(100 \mathrm{mg})$ with $20 \%$ aqueous $\mathrm{NaOH}(5 \mathrm{~mL})$ in benzene $(25 \mathrm{~mL})$ monitored by ${ }^{1} \mathrm{H}-\mathrm{NMR}$ spectroscopy. The stirring time ranged from $3 \mathrm{~h}$ (1a) to overnight (1c), depending on the porphyrin system employed. When the chemical shifts of the paramagnetic pyrrolic protons at $24 \mathrm{ppm}$ in ${ }^{1} \mathrm{H}-\mathrm{NMR}$ disappeared, $30 \mathrm{~mL}$ water was added into the reaction to precipitate desired dimanganese(III)- $\mu$-oxo compounds. The $\mu$-oxo-dimer products were collected by vacuum filtration and washed with water, and dried in air. The $\left[\mathrm{Mn}^{\mathrm{III}}(\text { Por })\right]_{2} \mathrm{O}$ products were further purified by recrystallization in benzene and cyclohexane, then fully dried in vacuum. 
4.3. General procedure for photolysis of dimanganese(III) bis-porphyrin $\left[\mathrm{Mn}^{\mathrm{III}}(\mathrm{Por})\right]_{2} \mathrm{O}$.

When the benzene solution of $\mathbf{1}$ at desired concentration $\left(c a .1 .5 \times 10^{-5} \mathrm{M}\right)$ was irradiated with a $120 \mathrm{~W}$ of visible light at ambient temperature, the formation of porphyrin-manganese(IV)oxo species 2 was complete in $c a .3$ to 4 min monitored by UV-visible spectroscopy. Reactions of oxo-species 2 with excess cyclohexene $(0.5 \mathrm{M})$ were conducted in a solution at $23 \pm 2{ }^{\circ} \mathrm{C}$, and the observed rates were monitored by the decay of the Soret absorption band of the oxo-species 2. The identity of $\mathbf{2}$ as $\mathrm{Mn}^{\mathrm{IV}}$ (Por)(O) was confirmed by producing the same species from chemical oxidation of corresponding manganese(III) chloride precursor with 25-fold excess of $\mathrm{PhI}(\mathrm{OAc})_{2}$ in benzene. When the solution of $\mathbf{1}$ in the presence of excess pyridine or triphenyl phosphine $(3 \mathrm{mM})$ was irradiated with visible light at ambient temperature, the time-resolved formation of manganese(II) products (3) was monitored by UV-visible spectroscopy during the course of irradiation up to $50 \mathrm{~min}$.

\section{Acknowledgments}

This work was supported by the National Science Foundation (CHE 1464886) and Kentucky EPSCoR program (REG 2015). K. W. Kwong is thankful to the Graduate School of WKU for a Graduate Student Research Fellowship (GSRF).

Abbreviations of porphyrin ligands used in this work: $\mathrm{Por}=$ porphyrin; $4-\mathrm{CF}_{3} \mathrm{TPP}=5,10,15,20$ tetra(4-trifuoromethylphenyl)porphyrin dianion; 4-FTPP = 5,10,15,20-tetra(4fuorophenyl)porphyrin dianion TPP = 5,10,15,20-tetraphenylporphyrin dianion; 


\section{References}

[1] J.E. Baeckvall, Modern oxidation methods, Wiley-VCH Verlag, Weinheim, 2004.

[2] A.E. Shilov, G.B. Shulpin, Chem. Rev. 97 (1997) 2879-2932.

[3] I.G. Denisov, T.M. Makris, S.G. Sligar, I. Schlichting, Chem. Rev. 105 (2005) 2253-

2277.

[4] P.R. Ortiz de Montellano (Ed.), Cytochrome P450 Structure, Mechanism, and Biochemistry, 3rd ed., Kluwer Academic/Plenum, New York, 2005.

[5] B. Meunier, Chem. Rev. 92 (1992) 1411-1456.

[6] R.A. Sheldon, Metalloprophyrins In Catalytic Oxidations, Marcel Dekker, New York, 1994.

[7] T. Punniyamurthy, S. Velusamy, J. Iqbal, Chem.Rev. 105 (2005) 2329-2363.

[8] C.-M. Che, J.-S. Huang, Chem. Commun. (2009) 3996-4015.

[9] B. Meunier (Ed.), Metal-Oxo and Metal-Peroxo Species in Catalytic Oxidations, Springer-Verlag, Berlin, 2000.

[10] M. Costas, M.P. Mehn, M.P. Jensen, L. Que, Chem. Rev. 104 (2004) 939-986.

[11] V.K. Yachandra, K. Sauer, M.P. Klein, Chem. Rev. 96 (1996) 2927-2950.

[12] J.T. Groves, J. Lee, S.S. Marla, J. Am. Chem. Soc. 119 (1997) 6269-6273.

[13] N. Jin, J.T. Groves, J. Am. Chem. Soc. 121 (1999) 2923-2924.

[14] J.T.K. Groves, William J., Jr.; Haushalter, Robert C., J. Am. Chem. Soc. 102 (1980) 6375-6377.

[15] C.L. Hill, B.C. Schardt, J. Am. Chem. Soc. 102 (1980) 6374-6375.

[16] M. Schappacher, R. Weiss, Inorg. Chem. 26 (1987) 1189-1190.

[17] R.S. Czernuszewicz, Y.O. Su, M.K. Stern, K.A. Macor, D. Kim, J.T. Groves, T.G. Spiro, J. Am. Chem. Soc. 110 (1988) 4158-4165.

[18] K. Ayougou, E. Bill, J.M. Charnick, C.D. Garner, D. Mandon, A.X. Trautwein, R. Weiss, H. Winkler, Angew. Chem. Int. Ed. Engl. 34 (1995) 343-346.

[19] K.S. Suslick, R.A. Watson, Inorg. Chem. 30 (1991) 912-919.

[20] K.S. Suslick, R.A. Watson, New J. Chem. 16 (1992) 633-642.

[21] R. Zhang, M. Newcomb, J. Am. Chem. Soc. 125 (2003) 12418-12419.

[22] R. Zhang, R.E.P. Chandrasena, E. Martinez, II, J.H. Horner, M. Newcomb, Org. Lett. 7 (2005) 1193-1195.

[23] R. Zhang, D.N. Harischandra, M. Newcomb, Chem. Eur. J. 11 (2005) 5713-5720.

[24] M. Newcomb, R. Zhang, R.E.P. Chandrasena, J.A. Halgrimson, J.H. Horner, T.M.

Makris, S.G. Sligar, J. Am. Chem. Soc. 128 (2006) 4580-4581.

[25] Z. Pan, R. Zhang, L.W.M. Fung, M. Newcomb, Inorg. Chem. 46 (2007) 1517-1519.

[26] R. Zhang, M. Newcomb, Acc.Chem. Res. 41 (2008) 468-477.

[27] R. Zhang, J.H. Horner, M. Newcomb, J. Am. Chem. Soc. 127 (2005) 6573-6582.

[28] J.P. Collman, P.S. Wagenknecht, J.E. Hutchison, Angew. Chem. 106 (1994) 1620-1639.

[29] J. Rosenthal, J. Bachman, J.L. Dempsey, A.J. Esswein, T.G. Gray, J.M. Hodgkiss, D.R. Manke, T.D. Luckett, B.J. Pistorio, A.S. Veige, D.G. Nocera, Coord. Chem. Rev. 249 (2005) 1316-1326.

[30] M.W. Peterson, D.S. Rivers, R.M. Richman, J. Am. Chem. Soc. 107 (1985) 2907-2915. [31] I.M. Wasser, H.C. Fry, P.G. Hoertz, G.J. Meyer, K.D. Karlin, Inorg. Chem. 43 (2004) 8272-8281. 
[32] C.J. Chang, E.A. Baker, B.J. Pistorio, Y. Deng, Z.-H. Loh, S.E. Miller, S.D. Carpenter, D.G. Nocera, Inorg. Chem. 41 (2002) 3102-3109.

[33] B.J. Pistorio, C.J. Chang, D.G. Nocera, J. Am. Chem. Soc. 124 (2002) 7884-7885.

[34] J. Rosenthal, B.J. Pistorio, L.L. Chng, D.G. Nocera, J. Org. Chem. 70 (2005) 1885-1888.

[35] J. Rosenthal, T.D. Luckett, J.M. Hodgkiss, D.G. Nocera, J. Am. Chem. Soc. 128 (2006) 6546-6547.

[36] D.N. Harischandra, G. Lowery, R. Zhang, M. Newcomb, Org. Lett. 11 (2009) 2089-2092.

[37] R. Zhang, E. Vanover, T.-H. Chen, H. Thompson, Appl. Catal. A 465 (2013) 95-100.

[38] E. Vanover, Y. Huang, L. Xu, M. Newcomb, R. Zhang, Org. Lett. 12 (2010) 2246-2249.

[39] R. Zhang, E. Vanover, W.-L. Luo, M. Newcomb, Dalton Transactions 43 (2014) 87498756.

[40] C.-C. Guo, H.-P. Li, J.-B. Xu, J. Catal. 185 (1999) 345-351.

[41] C. Abebrese, Y. Huang, A. Pan, Z. Yuan, R. Zhang, J. Inorg. Biochem. 105 (2011) 15551561 .

[42] K.W. Kwong, T.H. Chen, W. Luo, H. Jeddi, R. Zhang, Inorg. Chim. Acta 430 (2015) 176-183.

[43] M. Hoshino, Y. Nagashima, H. Seki, M.D. Leo, P.C. Ford, Inorg. Chem. 37 (1998), 2464-2469.

[44] A.D. Adler, F.R. Longo, J.D. Finarelli, D. Goldmacher, J. Assour, L. Korsakoff, J. Org. Chem. 32 (1967) 476.

[45] A.D. Adler, F.R. Longo, F.K. Kampas, J., J. Inorg. Nucl. Chem. 32 (1970) 2443-2445. 


\section{Graphic Abstract:}
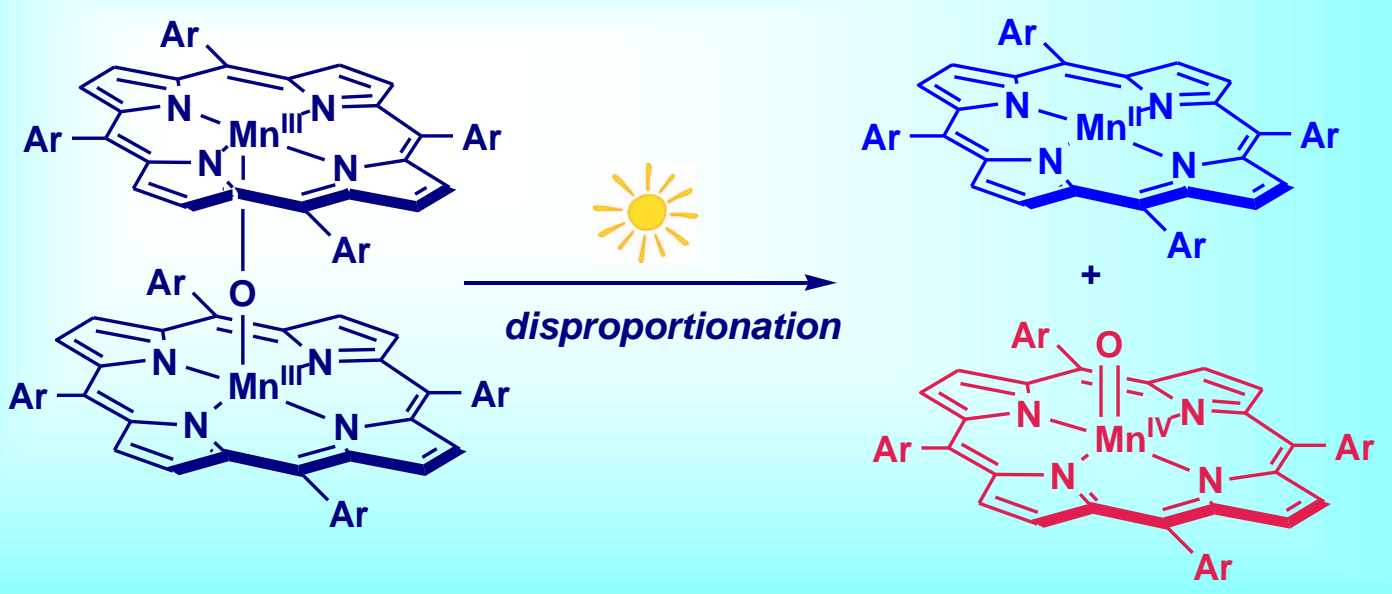
Visible light photolysis of bis-porphyrin-manganese(III) $\mu$-oxo dimers gave porphyrinmanganese(II) and manganese(IV)-oxo species that can be directly observed. 